\title{
Los arrendamientos vacacionales sometidos a la Ley de Arrendamientos Urbanos
}

\author{
Os aluguéis de férias submetidos à Lei de Arrendamentos Urbanos \\ Vacational rentals provided by the Urban Leases Law
}

José María Botello Hermosa*

\section{Resumen}

\begin{abstract}
En este artículo vamos a estudiar uno de los arrendamientos más importantes de nuestro ordenamiento jurídico especialmente utilizado durante los periodos vacacionales; el tradicional alquiler vacacional sometido a la L.A.U. como un tipo de arrendamiento celebrado por temporada. Se trata de un tipo de arrendamiento que, tradicionalmente, ha ocupado un lugar hegemónico, pero que, sin embargo, durante los últimos años, debido especialmente a la irrupción de los denominados "alquileres turísticos", se ha visto muy cuestionado, hasta el punto de pensarse una actividad ilegal por mucho de los arrendadores, como así pudiera desprenderse de la lectura del apartado e) del art. 5 que aporta la nueva Ley $4 / 2013$, de 4 de junio, de medidas de flexibilización y fomento del mercado del alquiler de viviendas, aunque nada más lejos de la realidad.
\end{abstract}

Palabras clave: Alquiler vacacional. Arrendamiento por temporada. Ley de arrendamientos Urbanos. Edificación habitable. Alquiler turístico.

\section{Resumo}

Neste artigo, estudamos uma das espécies contratuais mais utilizadas durante as férias em nosso país: os contratos de aluguel de férias, submetidos à Lei de Arrendamento Urbano, como um subtipo dos arrendamentos por temporada. Trata-se de um modelo contratual que tradicionalmente tem ocupado um lugar hegemônico, mas que, nos últimos anos, com a emergência dos aluguéis turísticos, teve sua relevância bastante diminuída ao ponto de tornar sua aplicação subsidiária, o que não é ilegal, como se poderia entender da leitura em apartado do artigo 50, alínea "e", da Lei 4/2013, de 4 de junho de 2013, sobre medidas de flexibilização e fomento do mercado de aluguéis.

Palavras-chave: Aluguel de férias. Arrendamento por temporada. Lei de Arrendamentos Urbanos. Edificação habitável. Aluguel turístico.

\section{Abstract}

In this article, we will study one of the most commonly used contract type in our country, the vacation rental agreements subject to the L.A.U, as a subtype of the seasonal leases. Traditionally, this contractual model occupies an hegemonic position concerning its use but with these past few years and the emergence of tourist rentals, its relevance greatly reduced and now only has the role/ the function of a supplemental application, not illegal as one could understand with the reading of the article 5(e) provided by the new Law 4/2013, of June 4th, about flexibility measures and the promotion/ development of the rental housing market.

Keywords: Vacationals rentals. Seasonal leases. Urban Leases Law. Residential building. Tourist rent.

\section{Introduccion}

Vamos a centrarnos en este artículo en uno de los arrendamientos más utilizados durante las temporadas vacacionales en España, que, curiosamente, no viene específicamente identificado en la 
normativa arrendaticia, sino que se deduce de la lectura de la norma. Vamos a analizar el "arrendamiento de vivienda por temporada vacacional".

Cada año, en nuestro país, un gran número de familias se trasladan a la costa o las zonas de montaña durante las temporadas vacacionales para desconectar de sus rutinas y disfrutar de unas reparadoras estancias, generalmente en la época de verano y de invierno, con la necesidad lógica de tener que satisfacer una necesidad de alojamiento que, excluyendo las pernoctaciones en hoteles y en apartamentos turísticos, se han resuelto mediante el alquiler de viviendas particulares que, en la práctica, se acordaban mediante la intermediación de alguna inmobiliaria o, directamente, mediante el contacto entre los propios particulares. ¿Quién no ha visto alguna vez un cartel con el letrero de "se alquila"? Como decimos, se trata de un tipo de alquiler que ha sido clave en nuestro país, enormemente utilizado y regulado mediante la Ley de Arrendamientos Urbanos (en adelante L.A.U.), pero que, cierto es, a medida que pasa el tiempo y la tecnología avanza, pareciera que comienza a rezagarse en un discreto segundo plano.

Pues bien, en este artículo vamos a analizar el clásico "alquiler vacacional" que se ha usado en España para los alquileres temporales de forma hegemónica hasta aproximadamente el año 2013, con la modificación de la L.A.U., especialmente con el apartado e) del art. 5, donde pudiera parecer que quedan en un margen de legalidad incierta, creándose una serie de dudas e incertidumbres que, precisamente, nos llevan a la elaboración de este trabajo con la finalidad de arrojar luz sobre el mismo. Tal es la incertidumbre jurídica que orbita actualmente alrededor de este tipo contractual que, muchos de los arrendadores que tradicionalmente recurrían al mismo, han dejado de emplearlo por temor a cometer algún tipo de irregularidad jurídica.

Por otro lado, a pesar de la existencia de otros tipos de contratos de alquiler de vivienda en épocas vacacionales, como veremos posteriormente, nos centraremos especialmente en el denominado "de uso vacacional", por la especial trascendencia que ha tenido a lo largo de los años en nuestro país, y porque a pesar de que recientemente ha irrumpido una nueva modalidad contractual que, parece ser, está invadiendo casi todo su ámbito de actuación, aun resiste, y mejor de lo que muchos pudieran pensar.

\section{Aspectos Generales}

\subsection{Delimitacion conceptual}

Como decíamos en la Introducción, este tipo de contratos no viene específicamente delimitado en la L.A.U., sino que se extrae de lo dispuesto en el art. 3. 2, cuando dispone "En especial, tendrán esta consideración los arrendamientos de fincas urbanas celebrados por temporada, sea ésta de verano o cualquier otra [...]". Así pues, se engloba este tipo de contrato dentro de una noción más general a la de "vacacional", como es la de "por temporada".

Para ofrecer una mejor comprensión del contexto donde se engloban estos alquileres, a continuación ofreceremos una panorámica de los arrendamientos urbanos en general y, progresivamente, abordaremos el que nos interesa.

\subsection{Clasificacion de los arrendamientos urbanos según la L.A.U. de 1994}

Como decimos, los alquileres vacacionales se engloban dentro de la figura contractual recogida por el art. 3. 2 de la L.A.U., que define y concibe los contratos temporales en contraposición a los contratos recogidos en el art. 2, es decir, los arrendamientos de vivienda. Así, el art. 3 de la L.A.U., cuyo título es "arrendamientos para uso distinto del de vivienda", dispone lo siguiente:

1. Se considera arrendamiento para uso distinto del de vivienda aquel arrendamiento que, recayendo sobre una edificación, tenga como destino primordial uno distinto del establecido en el artículo anterior. 
2. En especial, tendrán esta consideración los arrendamientos de fincas urbanas celebrados por temporada, sea ésta de verano o cualquier otra, y los celebrados para ejercerse en la finca una actividad industrial, comercial, artesanal, profesional, recreativa, asistencial, cultural o docente, cualquiera que sean las personas que los celebren.

De la lectura de este apartado, extraemos efectivamente que los arrendamientos por temporada se configuran en contraposición a los arrendamientos del art. 2, pero también en comparación a aquellos que se celebran para celebrarse en la finca una actividad industrial, comercial, artesanal, etc., los cuales vamos a englobar bajo el concepto de "arrendamientos de local de negocio". De este modo, con un primer análisis de los arts. 2 y 3 de la L.A.U., vemos que esta norma divide los arrendamientos urbanos en tres categorías: "de vivienda", "de local de negocio" y, finalmente, "por temporada", sobre los que profundizaremos posteriormente. Esta clasificación cobra todo su sentido cuando analizamos la evolución histórica que han seguido los arrendamientos urbanos en la normativa, especialmente los de temporada, con la elaboración de la L.A.U. del 94 que derogó la anterior del 64.

La inclusión de los "arrendamientos por temporada" en la L.A.U. del 94 tuvo una activa tramitación parlamentaria que se refleja en las numerosas modificaciones que sufrió el primigenio proyecto de Ley ya que, en la norma predecesora, la del 64 , en su art. 2. 1, se excluía expresamente de su ámbito de aplicación este tipo de arrendamientos. Sin embargo, en la L.A.U. del 94, el legislador ha optado por englobarlos dentro de su articulado conjuntamente con los arrendamientos celebrados para ejercer una actividad industrial, comercial, artesanal, profesional, recreativa, asistencial, cultural o docente, es decir, con los antiguos arrendamientos de local de negocio que, por el contrario, sí que se incluían en el ámbito de aplicación de la normativa, concretamente en el anterior art. 1. De esta forma, el legislador optó por dividir el antiguo artículo 1, que se componía por los arrendamientos "destinados a vivienda" y "los de local de negocio", en dos nuevos artículos diferenciados, como son el art. 2, compuesto por los "arrendamientos de vivienda", y el ambiguo art. 3, que engloba a todos aquellos contratos destinados a un uso distinto del anterior, haciendo especial referencia a los anteriores "de local de negocio" y de los celebrados "por temporada". Con esta decisión, el legislador equipara, en cierto modo, a los arrendamientos por temporada con aquellos celebrados para desarrollar una actividad empresarial, industrial, comercial etc., decisión que ha causado perplejidad y rechazo por parte de la doctrina, como es el caso de ROJO AUJURIA (1995, p. 77), que se pregunta qué tienen en común los arrendamientos de temporada con aquellos celebrados para ejercerse una actividad industrial, comercial, artesanal, profesional etc., o también YUFERA SALES (2000, p. 64), que expone que no obedece a ningún criterio lógico el incluir en la legislación especial arrendaticia los contratos de temporada.

Así las cosas, a efectos prácticos de nuestro trabajo, dividiremos los arrendamientos urbanos en tres categorías: "de vivienda", "de local de negocio" y, finalmente, " por temporada", modalidad en la que nos centraremos a continuación.

\subsection{El alquiler vacacional como una modalidad de arrendamiento urbano celebrado por temporada}

Las diferentes acepciones y nombres que recibe el arrendamiento por temporada pueden generar confusión al pensar que, si existen diferentes tipos, pudieran tener un ámbito de aplicación y una regulación normativa distinta. Nada más lejos de la realidad. El hecho es que, una misma figura jurídica, el arrendamiento por temporada (diferenciada de otros arrendamientos que también se destinan a un uso distinto del de vivienda, como pudieran ser los celebrados para industria, o para llevar a cabo un negocio, etc.) recibe diferentes acepciones en función de la causa-origen que dé lugar a la celebración del contrato. Esta circunstancia no significa que estas nociones constituyan "per se" diferentes tipos de arrendamientos con características diferentes entre ellos, sino que tan solo son formas diferentes de denominar al mismo tipo contractual, el de arrendamiento temporal. No olvidemos que los alquileres temporales se constituyen en contraposición a los celebrados para satisfacer una necesidad permanente de vivienda y los celebrados para local de negocio. 
Así pues, dependiendo de la causa que origine la celebración del arriendo por temporada, distinguiremos entre diferentes modelos.

\section{a) De segunda residencia}

Entiendo que esta acepción del arrendamiento por temporada se origina por mera comparación terminológica con los arrendamientos de vivienda que se destinan a satisfacer la necesidad permanente de una vivienda (art. 2 L.A.U.), es decir, a satisfacer la necesidad de su primera residencia. Si existe un tipo de arrendamiento que se destina a satisfacer la primera residencia del inquilino, por contraposición, deberá existir otro que se destine a satisfacer una necesidad de segunda residencia.

A partir de este punto, en el supuesto de que un arrendatario, con la necesidad permanente de vivienda satisfecha, celebrase un arrendamiento de alguna vivienda, el uso al que se debería destinar debería ser uno diferente del de satisfacer la necesidad permanente/primera de vivienda. Debería tener como destino un uso temporal de vivienda, o lo que es lo mismo, un uso de segunda residencia, ya que la necesidad permanente de vivienda se encuentra ya satisfecha con el primer arrendamiento. A titulo de ej., podríamos comentar el supuesto de una persona que, habiendo encontrado trabajo en una ciudad diferente a la suya, una vez trasladado y habiendo satisfecho su necesidad permanente de vivienda, le gustaría poder regresar a su entorno a ver a su familia y, para ello, arrienda otra vivienda en su ciudad natal. En este supuesto, el sujeto celebraría un arrendamiento de segunda residencia ya que la necesidad permanente de vivienda o de primera residencia la satisface en la nueva ciudad en la cual tiene su residencia habitual.

Otro ejemplo podría ser el supuesto en el que un trabajador fuese trasladado a otra ciudad por motivos laborales para un tiempo predeterminado con el fin de desempeñar una tarea concreta, volviendo a su puesto natural tras la finalización de la misma. En este caso, el contrato que celebrase en la ciudad de destino sería un arrendamiento temporal, un arrendamiento de segunda residencia celebrado únicamente por el tiempo que de duración del trabajo. Se trataría de una necesidad temporal de vivienda, únicamente por el tiempo que durase ese trabajo, ya que la necesidad permanente estaría ya cubierta con su domicilio presente.

En conexión con estos ejemplos, situamos el art. 7.1 de la L.A.U. que indica que en los supuestos en los cuales el arrendatario deje de tener en la finca arrendada su vivienda permanente, ésta no dejará de servir al uso de vivienda permanente al que se destinó en los casos en que permanezcan en la misma su cónyuge no separado legalmente o de hecho o sus hijos dependientes.

\section{b) Por temporada académica}

Este concepto de arrendamiento por temporada, al igual que todos los arrendamientos destinados a un uso distinto del de vivienda, tampoco satisface una necesidad permanente de vivienda ${ }^{1}$.

Esta acepción proviene, obviamente, de la causa que lo motiva, la necesidad temporal de una edificación habitable prescrita por una temporada académica. Este concepto engloba aquellos arrendamientos cuya causa original sea por motivos académicos sin importar la duración pactada para el contrato, sino la duración del periodo académico que genera causa de celebración del mismo.

Así, el ejemplo tipo se da cuando un estudiante se traslada a otra ciudad para llevar a cabo sus estudios y necesita una vivienda durante ese periodo, viéndose en la obligación de llevar a cabo un arrendamiento para poder vivir allí durante el tiempo que dure el curso. En esos casos se celebran contratos de arrendamiento por temporada académica, habitualmente de septiembre a principios de julio.

El dato determinante de que el alquiler sea temporal no lo determinará el plazo que las partes acuerden en el contrato, sino la causa que genera que se celebre ese acuerdo: realizar los estudios

En el mismo sentido, Colina Garea, Rafael (1998, p. 3). 
académicos. La causa será la necesidad temporal de una vivienda por el tiempo que dure el curso y el objeto deberá ser una edificación habitable que sirva para el uso al que se destina, habitar en ella.

\section{c) De temporada vacacional, o alquileres vacacionales}

Al igual que en los otros "modelos" de arrendamientos por temporada, el elemento determinante por el que podemos hacer esta sutil clasificación, es la causa que origina la celebración del contrato; ya sea para satisfacer una necesidad académica, para una necesidad de segunda residencia o, en este caso, por una necesidad durante las vacaciones.

Como su propio nombre indica, este modelo de arrendamientos temporales la reciben aquellos alquileres de viviendas que se originen por periodos vacacionales, generalmente durante los meses de verano e invierno. De este modo, la causa que da pie a su celebración y que, sutilmente, la diferencia del resto, es que en estos supuestos la intención es la de disfrutar, durante un tiempo predeterminado, de unas vacaciones, para lo cual se genera una necesidad de vivienda - de una edificación habitable- que permita que la finalidad del acuerdo (disfrutar de unas vacaciones) se lleve a cabo con normalidad. Piénsese, a título de ejemplo, en una familia que desea pasar una quincena en alguna localidad de la costa y alquila una vivienda. En estos casos, donde no se satisface la necesidad permanente de vivienda, el contrato de arrendamiento, denominado "por temporada vacacional", entiendo que deberá celebrarse sobre una edificación habitable por el hecho de que se destina a satisfacer una necesidad temporal de vivienda, para una época estival.

Como posteriormente veremos, esta acepción de los arrendamientos por temporada presenta grandes similitudes con otro tipo de arrendamientos, también celebrados por temporada, que se rigen por una normativa especial propia, planteándonos dudas y generando confusión en cuanto al deslinde de su ámbito de aplicación entre la L.A.U. y su normativa específica.

\section{Los Arrendamientos Vacacionales}

En este apartado vamos a analizar los aspectos esenciales de este tipo de alquileres, permitiéndonos poder identificarlos fácilmente, lo que nos servirá para posteriormente compararlos con otros tipos de alquileres con los que, frecuentemente, se suelen confundir o sobre los cuales existen dudas en cuanto a su delimitación.

\subsection{Caracteristicas}

\subsubsection{Especial consideración en la norma}

Se trata de un aspecto que ya hemos tratado anteriormente. Así, los arrendamientos vacacionales tienen una especial consideración en la regulación en el artículo 3. 2 de la L.A.U., que dispone: "En especial, tendrán esta consideración los [...] celebrados por temporada, sea ésta de verano o cualquier otra $[\ldots .$. ".

Representan un tipo de arrendamiento por temporada especialmente reflejado en la normativa estatal, con una especial relevancia en nuestro sistema normativo. Es decir, que no se trata de un tipo alquileres que se dan de forma aislada, no. Siendo por ello necesario una exploración en profundidad de los mismos.

\subsubsection{Elementos esenciales del contrato}

En el Ordenamiento Jurídico español, según lo dispuesto por el art. 1261 C.C., todo contrato requiere para su existencia de consentimiento, objeto y causa. En el caso de los arrendamientos urbanos, como dispone el art. 1 de la L.A.U., el objeto cierto del contrato está formado por la finca/edificación urbana que se arrienda, la causa será el uso al que se destina el arrendamiento (satisfacer una necesidad permanente 
de vivienda o a un uso distinto) y el consentimiento, sobre el que no profundizaremos, ya que se manifiesta por el mero concurso de la oferta y la aceptación sobre la finca urbana y sobre el uso al que se vaya a destinar.

\section{a) El destino primordial del contrato}

Este primer elemento nos servirá para delimitar cuándo el alquiler de una vivienda deberá entenderse sometido a lo previsto para los arrendamientos "de vivienda" del art. 2, o por el contrario, por lo dispuesto para los "alquileres vacacionales", previsto en el art. 3. 2.

El art. 2. 1 de la L.A.U. regula los arrendamientos de vivienda, y dispone que "se considera arrendamiento de vivienda aquel arrendamiento que recae sobre una edificación habitable,cuyo destino primordial sea satisfacer la necesidad permanente de vivienda del arrendatario". Por otro lado, el art. 3, en su apartado 1, regula los arrendamientos para uso distinto del de vivienda que "se considera arrendamiento para uso distinto del de vivienda aquel arrendamiento que, recayendo sobre una edificación, tenga como destino primordial uno distinto del establecido en el artículo anterior".

Así pues, de la lectura conjunta de estos artículos se percibe que la principal diferencia que se dilucida entre ambos tipos es la causa que los motiva, o lo que es lo mismo, el uso al que se destinan, satisfacer la necesidad permanentede vivienda en los primeros, y uno distinto del establecido en el apartado anterior, es decir, un uso diferente al de la necesidad permanente de vivienda, en los segundos.

El hecho de que un arrendamiento se destine a un uso distinto del de vivienda no significa que ese contrato no se pueda celebrar para un uso de vivienda en sentido literal, pues el título del art. 3 -arrendamientos para un uso distinto del de vivienda- regula jurídicamente aquellos arrendamientos que se destinen a un uso que no sea el de satisfacer la necesidad permanente del arrendatario ya que esos vienen regulado en su artículo precedente, los arrendamientos del art. 2 : el arrendamiento de vivienda. A lo que realmente aluden estos arrendamientos es a que se destinen a un uso que no sea el de satisfacer la necesidad permanente de vivienda o una necesidad de una primera residencia del arrendatario. Así, los alquileres vacacionales se caracterizan por destinarse a satisfacer una necesidad temporal de vivienda, por el tiempo que duren las vacaciones. Considero que su destino primordial es, al igual que en los arrendamientos de vivienda, la satisfacción de una necesidad vivienda ${ }^{2}$, de una edificación habitable, que, al contrario de aquellos, no se destina a satisfacer una necesidad permanente, sino vacacional. En estos términos, el aspecto vacacional se presenta como un elemento clave para determinar el artículo de la L.A.U. al que deben someterse.

Llegados a este apartado, cabría plantearse las siguientes cuestiones ¿Qué se entiende por temporalidad? ¿Cómo se cuantifica la duración de lo que debería entenderse como vacaciones? Pues bien, este interrogante ya lo ha resuelto nuestro Alto tribunal indicando reiteradamente que el requisito de la temporalidad o de la permanencia de la ocupación guarda relación no con el plazo de duración simplemente cronológico por que se pacta la duración del contrato sino con la finalidad a que va encaminado ${ }^{3}$. Es decir, que el verdadero criterio determinante para calificar cuándo un alquiler es vacacional, y por extensión temporal (art. 3. 2), en detrimento de vivienda (art. 2), no será, como ya hemos visto, ni su objeto ni la duración cronológica temporal del $\mathrm{mismo}^{4}$, sino la finalidad a la que destine el contrato, el cual deberá ser diferente a un uso permanente de vivienda. ${ }^{5}$ En sentido contrario a esta concepción de la temporalidad se pronuncian, entre otros, Ordás Alonso, Valladares Rascon (2013, p. 115) y Davila Gonzalez (1994, p. 31),

En el mismo sentido, GUILARTE ZAPATERO, V. (1995, p. 68). "Así, respecto de los arrendamientos celebrados por temporada [...] aun celebrados para vivienda, por su propia esencia resultan incompatibles con aquél (los arrendamientos de vivienda), al no reunir los requisitos del destino primordial y de servir a la necesidad permanente de aquella [...]" Además, dentro de los requisitos que cita el autor que no reúnen, no indica que la edificación no es habitable.

SSTS 28 de enero 1960 (RJ 1960/445), 30 de junio 1976 (1976/3199), STS de 15 de diciembre de 1999 (RJ 199919352), FJ. $3^{\circ}$

Los contratos se podrán celebrar tanto por un verano como por dos, como por fines de semanas o semanas enteras, o días sueltosetc. La duración del arrendamiento es irrelevante a la hora de determinar los contratos por temporada.

En el mismo sentido ROJO AJURIA, L. (1995, p. 76). 
considerando que si el plazo es inferior a un año es lógico presumir que se trata de un arrendamiento de temporada.

En resumen, considero que la principal diferencia entre los arrendamientos de vivienda y los alquileres vacacionales, ${ }^{6}$ es la causa que motiva la celebración del contrato o el fin que persiguen con ello, que será o satisfacer una necesidad permanente de vivienda o una necesidad temporal de vivienda, pero atención, con la particularidad de que, además, en ambos casos, considero que deben tener el mismo objeto contractual: una vivienda que esté en condiciones de habitabilidad. ${ }^{7}$ Así, por mera comparación terminológica, si se cotejan los arrendamientos de viviendas con los de temporada, en este supuesto aquellos destinados a satisfacer la necesidad de una vivienda como segunda residencia, se deduce que, si existe un tipo de arrendamiento "de segunda residencia", obligatoriamente habrá de existir otro tipo de arrendamiento "de primera residencia", que viene representado por los arrendamientos de de vivienda del art. 2. ${ }^{8}$ Por consiguiente, ambas modalidades deberán tener el mismo objeto del contrato, una vivienda habitable capaz de satisfacer tanto la necesidad de primera como de segunda residencia.

Me parece incongruente que para los arrendamientos que se destinen a vivienda se imponga por Ley la obligación de que la edificación sea habitable pero no así en los casos en que se destine a un uso temporal. A título de ejemplo, si una pareja quisiera arriendar una vivienda, en el caso de que la destinen para satisfacer la necesidad de primera residencia la Ley exige que ésta sea habitable, sin embargo si, en lugar de a primera residencia, quisieran arrendarla para un uso vacacional, la exigencia de habitabilidad ya no es imperativa y, por ende, no sería, en principio, un requisito obligatorio.

Por ello, entiendo que ambos tipos de arrendamiento comparten el mismo objeto contractual, una vivienda en condiciones de habitabilidad, que será destinada a satisfacer una necesidad de vivienda que, dependiendo la finalidad que se le dé, se calificara el contrato de distinta forma, con las consecuencias jurídicas que de ello se deriva.

\section{b) Objeto del contrato: ¿Edificación, o edificación habitable?}

El art. 2 de la L.A.U. dispone que el objeto de los arrendamientos de vivienda deberá ser una edificación habitable: "se considera arrendamiento de vivienda aquel arrendamiento que recae sobre una edificación habitable, cuyo destino primordial sea satisfacer la necesidad permanente de vivienda del arrendatario". Y, sin embargo, en el art. 3. 1 dispone que los arrendamientos para uso distinto del de vivienda recaerán sobre una edificación sin el requisito de habitable": "se considera arrendamiento para uso distinto del de vivienda aquel arrendamiento que, recayendo sobre una edificación, tenga como destino primordial uno distinto del establecido en el artículo anterior".

Como ya se ha desarrollado, el elemento principal que distingue estos arrendamientos es, "de facto", el destino primordial - o el uso- al que se destina pero, "de iure", la redacción de estos artículos nos

\footnotetext{
Y por extensión, los arrendamientos por temporada en general.

En el mismo sentido, VATIER FUENZALIDA, C. (1996, p. 75). En sentido análogo, COLINA GAREA (1998, p. 175) expresa la misma idea pero sobre los arrendamientos de temporada académica. Leyendo a GUILARTE ZAPATERO (1995, p. 63 y 67), podríamos deducir que se sitúa en esta misma línea pues cita que: "laedificación habitable [...] ha de reunir las indispensables condiciones objetivas para que en ella sea posible desenvolver las actividades domesticas de quienes moran en ella. Esta idea, en relación con la declaración en la que considera que "[...] el texto legal, al determinar el objeto de estos arrendamientos, habla simplemente de edificación y de edificación habitable [...] tal circunstancia no es decisiva ni suficiente para matizar la diferencia entre una y otra clase de arrendamientos, pues [...] es posible que sobre una edificación, idónea [...] para satisfacer la necesidad permanente de vivienda del arrendatario, se constituya un arrendamiento del otro tipo. Piénsese, por ejemplo, en el piso de un edificio arrendado [...] para servir de hogar de éste, pero no de forma primordial y continuada, como serían los casos de la segunda residencia o del arrendamiento por temporada", hace que, de la lectura conjunta de ambas declaraciones, dilucido que este autor considera que los arrendamientos por temporada deben tener como objeto del contrato una edificación habitable.

8 En el mismo sentido, dice O'CALLAGHAN (1995, p. 20) “[...] los arrendamientos de vivienda son aquellos dedicados a satisfacer la necesidad de vivienda primaria y permanente del arrendatario, su cónyuge o sus hijos dependientes [...]'. En los mismos términos. ROJO AJURIA, L. (1995, p. 68).

9 El requisito de habitabilidad, si se exigía en la L.A.U. de 1964 pero fue eliminado con carácter general a través de las enmiendas 254 y 255 del grupo socialista durante la tramitación del Proyecto de Ley, exigiéndose únicamente para los arrendamientos de vivienda, modificando así el art. 3 del proyecto de 1992, que disponía en su $1^{\circ}$ apartado: "Se considera arrendamiento para uso distinto del de vivienda el de fincas urbanas que recaiga sobre una edificaciones habitables cuyo destino primordial sea distinto del establecido en el artículo anterior".
} 
muestra que el objeto del contrato es distinto. Se dispone que, los arrendamientos de vivienda recaerán sobre una "edificación habitable" mientras que en los arrendamientos celebrados por temporada (art. 3), deberán celebrarse sobre una "edificación" sin el calificativo de habitable. Pudiera parecer que, de este modo, la hipótesis que anteriormente expuse (arrendamientos de vivienda y los celebrado por temporada tienen en común el mismo objeto del contrato, una edificación habitable) no se sustente debido a la supresión del adjetivo habitable, pero entiendo que no es así.

Considero que el hecho de que se suprima el adjetivo "habitable" en el art. 3 se debe a un motivo puramente clasificatorio por parte del legislador. Tenemos que recordar que el art. 3 , en su apartado 2 , además de regular los arrendamientos por temporada, también incluye los arrendamientos destinados a ejercer una actividad industrial, comercial, artesanal, profesional, etc. (los arrendamientos de local de negocio), siendo este el principal motivo por el que entiendo que el legislador, con la pretensión de acordar un objeto del contrato compatible con esos tipos de arrendamientos, optó por incluir únicamente el término "edificación" suprimiendo el calificativo de "habitable". Con esta decisión, el legislador puede incluir en una misma categoría dos tipos diferentes de arrendamiento. A sensu contrario, si se exigiera que el contrato se celebrase sobre una "edificación habitable", como se hace en el art. 2, sí existiría un límite a su ámbito de aplicación ya que aquellas edificaciones que no estén en condición de ser habitadas no se podrían englobar en esta categoría por no cumplir tal exigencia. La razón por la cual se exige el requisito de habitabilidad no supone ni una barrera ni ningún impedimento a que a los arrendamientos de temporada sí que se les debiera exigir (aunque fuese por jurisprudencial) el requisito de que la edificación sobre la que se celebrases debiera reunir las condiciones de habitabilidad en las mismas condiciones que a los arrendamientos del art. 2. Éste es el motivo por el que entiendo que solamente aparece el término "edificación" como el objeto de los arrendamientos por temporada sin la exigencia de la habitabilidad, creando así la duda acerca de si los arredramientos del art. 3.2, concretamente los celebrados por temporada (segunda residencia y los celebrados por temporada), podrían tener por objeto una edificación sin la condición de habitabilidad.

A mayor abundamiento, pienso que, por respeto a cualquier ser humano, la edificación que se arriende para ser habitada, ya sea para uso permanente o temporal, ha de ser habitable. De lo contrario, se podría aludir que estos arrendamientos no son conformes al uso al que se destinan ${ }^{10}$ (ser habitadas), pues no satisfacen la necesidad de vivienda la que un individuo o una familia desarrollen con normalidad y dignidad la intimidad de la existencia. A título de ejemplo, tengamos en cuenta el supuesto de hecho en el que una familia alquila una vivienda para 2 meses de vacaciones, y que el día que entran, no se encuentra en las mínimas condiciones de habitabilidad, imposibilitándoles disfrutar del inmueble con la normalidad que cabria esperarse. De seguir una interpretación literal del art. 3, se "estaría cumpliendo" con lo dispuesto en la norma y el objeto del contrato sería conforme a la L.A.U. ya que sería una edificación, sin importar la condición de habitabilidad. Pero en este supuesto, la realidad fáctica es que no se cumpliría con la causa o destino que motivó la celebración del contrato, esto es, para disfrutar temporalmente de una edificación habitable en la que desarrollar la intimidad de la existencia con total normalidad, adecuación y dignidad. Entiendo que el contrato no respetaría la causa o destino al que se destina y, por tanto, no debería considerarse válido (aunque, como ya he indicado, ciñéndonos a lo establecido en la L.A.U., sería legal y conforme a derecho). Este supuesto de hecho no estaría conforme a lo dispuesto en el Título VI (Del contrato de arrendamiento), Capítulo Segundo Sección Segunda (De los derechos y obligaciones del arrendador y arrendatario), cuyos artículos $1554.2^{\circ}$ y $3^{\circ}$ establecen que el arrendador "está obligado a hacer en ella (en la cosa objeto del contrato, es decir, en la edificación) durante el arrendamiento todas las reparaciones necesarias a fin de conservarla en estado de servir para el uso a que ha sido destinada, y a mantener al arrendatario en el goce pacifico del arrendamiento por todo el tiempo del contrato", seguido del $1555.2^{\circ}$, que añade que el arrendatario está obligado a "A usar de la cosa arrendada como un diligente padre de familia, destinándola al uso pactado; $y$, en defecto de pacto, al que se infiera de la naturaleza de la cosa arrendada según la costumbre de la tierra".

10 Respecto al concepto de la habitabilidad, el T.S. se ha pronunciado reiteradamente estableciendo que consiste en la aptitud de las viviendas, edificaciones o construcciones en general para ser utilizados conforme a su concreto y particular destino. (RJ 1992l7545). 
De esta lectura se desprende que, si se acuerda un arrendamiento de una vivienda con el fin de pasar en ella unas vacaciones, el arrendador tiene la obligación de que la edificación esté en las condiciones adecuadas para servir a ese uso al que se destina garantizándole el uso pacífico del arrendamiento, obligación relacionada con la del arrendatario que debe de destinarla exclusivamente para el uso que se pactó, es decir, no dedicarla a otros usos diferentes como por ej. llevar a cabo una actividad empresarial. Por tanto, este contrato no sería conforme al C.C, y considero que, no exigiendo la habitabilidad del objeto de los arrendamientos por temporada, se estaría dejando en una posición de vulnerabilidad y falta de protección total a los arrendatarios. Se podría generar un clima de inseguridad jurídica y se conseguiría un resultado inverso al perseguido por esta norma: el fomento del mercado inmobiliario en nuestro país.

Desde el punto de vista del objeto del contrato relaciono los arrendamientos de vivienda con los arrendamientos celebrados por temporada y, por ende, con los alquileres vacacionales, pues ambos deberían celebrarse sobre una edificación habitable pues, aunque el título que lo regula da lugar a confusión (arrendamiento para uso distinto del de vivienda), la causa que los fundamenta sería una necesidad temporal de vivienda, es decir, necesariamente una edificación habitable en la que pudiera satisfacerse, precisamente, la causa del contrato, como podría ser, a título de ejemplo, querer pasar una vacaciones en la playa. Bajo mi punto de vista, este apartado fundamenta la principal diferencia entre los dos tipos de arrendamientos analizados, lo que se resume en la satisfacción de una necesidad de vivienda habitable de forma permanente o temporal.

En resumen, bajo mi punto de vista, entiendo que los alquileres vacacionales deberán celebrarse siempre sobre una edificación habitable, aunque no venga así especificado en la L.A.U.

\subsubsection{Vivienda amueblada y en condiciones de uso inmediato}

Esta particularidad amplía la obligatoria condición de habitabilidad de la vivienda que acabamos de ver, pues no se podrá disfrutar verdaderamente del periodo vacacional sin estar debidamente amueblada y condicionada para su uso inmediato.

La exigencia de habitabilidad y uso inmediato se puede extraer de la corta duración de estos periodos vacacionales, que, con el paso del tiempo, van reduciéndose. No tendría sentido alquilar una vivienda con la finalidad de pasar un periodo vacacional de corta duración y que no estuviese debidamente amueblada y en condiciones para ser usada al instante. Se sobrentiende que, cuando alguien desea pasar una temporada en la playa o en la montaña con la intención de descansar, desconectar, olvidarse de la rutina, disfrutar, relajarse, etc., y no consideramos que tener que hacer una mudanza ayude a ello.

Este requisito, en mi opinión, se convierte en una condición obligatoria del contrato atendiendo a lo dispuesto en el Título VI (Del contrato de arrendamiento), Capítulo Segundo Sección Segunda (De los derechos y obligaciones del arrendador y arrendatario), cuyos artículos $1554.2^{\circ}$ y $3^{\circ}$ establecen que el arrendador "está obligado a hacer en ella (en la vivienda) durante el arrendamiento todas las reparaciones necesarias a fin de conservarla en estado de servir para el uso a que ha sido destinada, y a mantener al arrendatario en el goce pacifico del arrendamiento por todo el tiempo del contrato", seguido del $1555.2^{\circ}$, que añade que el arrendatario está obligado a " $A$ usar de la cosa arrendada como un diligente padre de familia, destinándola al uso pactado; $y$, en defecto de pacto, al que se infiera de la naturaleza de la cosa arrendada según la costumbre de la tierra".

De esta lectura se desprende que, si se acuerda un arrendamiento de una vivienda con el fin de pasar en ella unas vacaciones, el arrendador tiene la obligación de que la vivienda esté en las condiciones adecuadas para servir a ese uso al que se destina garantizándole el uso pacífico del arrendamiento, obligación relacionada con la del arrendatario que debe de destinarla exclusivamente para el uso que se pactó, es decir, no dedicarla a otros usos diferentes como por ej. llevar a cabo una actividad empresarial. Por tanto, este contrato no sería conforme al C.C, y consideramos que, no exigiendo la habitabilidad y la condición de que esté debidamente amueblada y en condiciones de uso inmediato, del objeto de los estos 
alquileres vacacionales, se estaría dejando en una posición de vulnerabilidad y falta de protección total a los arrendatarios.

Sobre este particular, se pronuncia en la misma línea la Audiencia Provincial de Madrid, que, en un litigio acerca de la habitabilidad de una vivienda durante un alquiler vacacional, señala que

[...] ha quedado acreditada la falta de limpieza y la inadecuación del apartamento arrendado para servir al uso que era destinado (alquiler de temporada de la primera quincena del mes de agosto) (...) este Tribunal debe forzosamente compartir (...) que el hoy apelante incumplió con la principal obligación asumida frente a la actora, esto es, proporcionar una vivienda amueblada y acondicionada para las vacaciones durante la primera quincena del mes de agosto, de tal manera que debe entenderse que la demandante no hubiera arrendado nunca el apartamento de conocer su estado de suciedad y la inadecuación de sus instalaciones. En definitiva, (...) entregó una cosa (...) inhábil en su conjunto, para el uso a que iba destinada, creando una insatisfacción objetiva y justificada de la arrendataria, según los usos normales.(...) forzoso es estimar acreditado el padecimiento psíquico sufrido por la demandante que vio transformadas sus lógicas expectativas de unos días plácidos de vacaciones, por una situación incómoda, tensa e inaceptable, que la obligó a buscar a toda prisa una nuevo alojamiento. (JUR 2010120360 - Audiencia Provincial de Madrid (Sección 20ª). Sentencia n. 574/2009, de 19 octubre.)

Asimismo, consideramos que esta particularidad es una forma de distinguir los alquileres vacacionales del resto de arrendamientos temporales, es decir, de los celebrados por periodos académicos o de los de segunda residencia, generalmente acordados por periodos anuales, en donde la exigencia de los muebles y del uso inmediato no presenta la misma relevancia. En esta línea, entendemos que la exclusión especifica del apartado e) del art. 5 se refiere exclusivamente a los alquileres vacacionales, y no al resto de arrendamientos temporales.

\subsection{Regimen juridico}

Al igual que el resto de arrendamientos que se destinan a un uso diferente del de satisfacer una necesidad permanente de vivienda, los "alquileres vacacionales" se regularán por lo dispuesto imperativamente en los Títulos I y IV de la L.A.U., por lo acordado inter partes y, en su defecto, por el Título III de los arrendamientos para unos distinto del de vivienda (excepto los arts. 32, 33 y 34, vinculados a los arrendamientos "de local de negocio") y, supletoriamente, por lo dispuesto en el Código Civil.

En primer lugar, se someten imperativamente a lo dispuesto en los Títulos I y IV, cuya consecuencia más relevante es, en caso que así lo determinen la comunidad autónoma, la obligatoriedad del depósito de una fianza de 2 mensualidades de la renta en un registro de la CC.AA. (art. 36). Este requisito resulta algo excesivo para este tipo de arrendamientos ya que, por lo general, suelen ser por estancias cortas y esta exigencia parece ilógica en comparación con la de los arrendamientos de vivienda a los que se les requieren únicamente una mensualidad.

Por otro lado, otra de las características relevantes de los "alquileres vacacionales", es la amplia libertad de pacto de la que gozan las partes del contrato para acordar aquello que estimen convenientes, y tan solo en defecto de acuerdo, se aplicará lo dispuesto en el Título III, como sucede en el caso del derecho de adquisición preferente del arrendatario (al art. 31, que se remite al 25), que se aplicará en el caso en que las partes no establezcan explícitamente lo contrario.

Finalmente, y de forma supletoria, se someterá a lo dispuesto por el C.C., concretamente a lo dispuesto en los Títulos II y VI, normativa de contratos y, específicamente, del contrato de arrendamiento.

\subsection{Arrendamientos celebrados por temporada vacacional pero excluidos del regimen juridico de la L.A.U.}

Existen algunos contratos de alquileres vacacionales que, a pesar de reunir los elementos esenciales de estos contratos, no se regulan por la L.A.U., sino a través de una normativa propia, generalmente 
aprobada por motivos de políticas económicas, dando como resultado, en muchos casos, una situación confusa e imprecisa en cuanto al ius cogens de los mismos.

Dentro de esta tipología de contratos, sobre los que no incidiremos en profundidad, podríamos destacar los siguientes.

\section{a) Los contratos complejos. Especial mención al contrato de Hospedaje}

Los contratos de "arrendamientos complejos" pueden dar lugar a confusión y hacernos pensar que son un tipo de alquiler vacacional regulado en la L.A.U., como pudieran ser los arrendamientos de vivienda o los celebrados por temporada, pero la realidad es distinta. Se trata de un tipo alquiler que se formalizan a través de la celebración de "contratos atípicos", es decir, carentes de una regulación legal propia y de una normativa concreta.

Representan un concepto jurídico elaborado por la doctrina ${ }^{11}$ para referirse a unos tipos de contratos que, en base al art. 1255 del C.C., se constituyen unificando una serie de contratos de diversa naturaleza jurídica que orbitan alrededor de un arrendamiento urbano, configurando entre todos ellos un único contrato "complejo" precisamente por esa pluralidad de contratos regulados por diversas normativas. Esto es, se forman a partir del alquiler de una vivienda, y en torno dicho alquiler orbitan otra serie de acuerdos bilaterales conectados al primero que se rigen cada uno por una normativa específica, conformando entre todos ellos un nuevo contrato único por un precio cierto. Sin embargo, este hecho plantea la duda acerca de cuál de todas esas normativas le será aplicable a este contrato único, la L.A.U., propia a los alquileres vacacionales, o las otras normas especificas que regularan el resto de acuerdos bilaterales.

Así, sobre esta cuestión, nuestra jurisprudencia se pronuncia definiendo el contrato de arrendamiento complejo como aquel que está constituido por un conjunto de negocios jurídicos bilaterales combinados, pactos lícitamente contraídos según el art. 1255 del C. Civil, y que por su naturaleza principal y características, no constituyen un arrendamiento simple o corriente, sino que aparecen investidos de una complejidad que determina que no puedan ser incluidos todos sus aspectos en el cauce del régimen jurídico simple y sencillo del contrato de arrendamiento de establecimiento industrial. ${ }^{12}$ Señala nuestro Alto Tribunal, a su vez, que supone el establecimiento a cargo del arrendatario de prestaciones que no son propias y específicas de la relación arrendaticia, o complementarias de ella. ${ }^{13}$

Recapitulando, los contratos de arrendamientos complejos, al recaer sobre un contrato principal de arrendamiento sobre el que se dan otras prestaciones adicionales de carácter principal, se diferencian de los contratos de arrendamientos por temporada y se excluyen del ámbito de aplicación de la L.A.U., aunque reúnan los requisitos para incluirse dentro de los arrendamientos del art. 3 de la L.A.U. Así pues,

\footnotetext{
En este sentido, ALBACAR entiende "son aquellos contratos unitarios, en los que además de prestaciones típicas del contrato de arrendamiento, acuerdan las partes otras principales que han de cohonestarse con aquellas, produciendo una mutación importante de su contenido o régimen", FUENTES LOJO opina que " los contratos de arrendamiento en los que las partes en uso de la autonomía de su voluntad disponían un contenido más complejo que el previsto en el Texto Refundido (L.A.U. 64), sin que con lo mismo se desvirtuara la tipicidad del contrato; ello a pesar de una jurisprudencia nada clara en este sentido. Estos contratos deberían someterse al régimen de la legislación especial. (STC 24 octubre de 1963, 10 de octubre de 1988)" VALPUESTA FERNANDEZ, M R. (1994). Articulo 3. Arrendamientos para uso distinto del de vivienda. En: Valpuesta Fernández, M ${ }^{\circ}$ (Coord.), Comentarios a La Nueva Ley de Arrendamientos Urbanos (p. 46). Valencia: Tirant lo Blanch. VATIER FUNZALIDA (1996, p. 60), a su vez, concibe los contratos de arrendamiento complejos como "aquellos contratos unitarios en los que se unen al arrendamiento prestaciones especiales de carácter principal, en términos tales que su resultado es un contrato nuevo y distinto". En comparación a estos contratos, escribe este autor que los arrendamientos mixtos, entendidos como aquellos a los que se añaden o yuxtaponen prestaciones accesorias, carecen de la entidad suficiente como para apartar el contrato de arrendamiento típico (por ej. los arrendamientos con opción a compra). Concluye indicando que La doctrina anterior entendía a los complejos excluidos y a los mixtos incluidos en el T.R. 64. Asimismo, DE DIEGO (1930, p. 245-246) lo califica como "contrato consensual por virtud del cual una persona se obliga a prestar a otra alojamiento y suministrarle alimentación mediante un precio". A su vez, YUFERA (2000, p. 67-68) concibe los contratos de arrendamientos complejos como "aquellos en que las partes pactan como cuestiones esenciales del contrato una serie de prestaciones ajenas a la relación arrendaticia y que son consustanciales al contrato, es decir, que no son ni accesorias, ni complementarias, ni eventuales". Para PÉREZ SERRANO (1930. p. 86), "la nota esencial y perdurable del contrato fue y sigue siendo el complexus jurídico formado por la cesión de habitaciones y de los servicios complementarios a la vivienda. Cuando él se da, tenemos contrato de hospedaje; cuando falta, no existe dicho contrato. El suministro de alimentos no influye de un modo decisivo en la existencia de aquél, aunque tenga notable importancia para la debida solución de algunos de sus aspectos".

Sts 18 abril 1989 (RJ 198913067).

13 Sts 21 febrero 2000 (RJ 2000, 1239), Sts 24 enero 2000 (RJ 2000, 115).
} 
sobre los arrendamientos complejos, tanto la doctrina ${ }^{14}$ como la jurisprudencia ${ }^{15}$ se decantan por excluirlos de la L.A.U.

Dentro de los contratos complejos, el más reputado ha sido siempre el de hospedaje, del que Castan Tobeñas (1956, p. 135-142) configura como aquel contrato complejo por el que una persona se obliga a prestar a otra alojamiento y, cuando menos, los servicios complementarios de vivienda, mediante un precio, celebrados en virtud del art. 1256 del CC.

b) Los contratos de aprovechamiento por turno o alquileres vacacionales por turno: La mal llamada "multipropiedad"16, o también conocido como "timesharing".

Este tipo de arrendamientos vacacionales "por turno", vienen recogidos en los arts. 1, 2, y 27 de la ley 4/2012, de 6 de julio, y representan, a grosso modo, un tipo especial de "alquiler vacacional" a través del cual se lleva a cabo un contrato de arrendamiento de una vivienda/alojamiento en una época determinada del año (con un mínimo de 7 días seguidos) y durante varios años diferentes, de tal forma que se asegura el derecho de uso y disfrute de dicho alojamiento/vivienda, únicamente durante un periodo determinado del año (generalmente durante el verano), durante varios años, evitándose así las molestias de tener que volver a celebrar cada año un nuevo contrato entre las mismas partes y sobre los mismos aspectos, y además, con derecho a la prestación de una serie de servicios complementarios (como puede ser la limpieza del apartamento a su llegada).

Su Régimen jurídico no es fácil de delimitar porque, además de que está sometido a una normativa en constante modificación, la Ley que actualmente lo regula, la citada Ley 4/2012, de 6 de julio, derivándose supletoriamente $^{17}$ a lo dispuesto para los arrendamientos vacacionales, regulados en el art. 3.2 de la L.A.U. De esta forma, nos planteamos el interrogante de qué normativa les será aplicable y en qué medida, al tratarse de dos normativas especiales y con diversas disposiciones imperativas. En este sentido, y de una forma escueta, considero que la L.A.U. no se podrá aplicar a este tipo de contratos, de tipología compleja, quedando por ello excluido de su ámbito de aplicación. Entiendo que la citada remisión a la L.A.U. fue un hecho desafortunado de la Ley 4/2012 de 6 de julio a la L.A.U. con la intención de evitar, sorprendentemente, posibles situaciones de contradicción entre ambas normas. ${ }^{18}$

En resumen, considero que estos contratos, a pesar de ser por temporadas vacacionales, reúnen el condicionante para ser calificados como "complejos", ya que además de la exigencia de que el arrendador deba ser un "empresario", han de prestarse una serie de servicios adicionales al de la vivienda. Así pues, la normativa aplicable sería la Ley 4/2012, de 6 de julio por ser más específica que la L.A.U., al haber sido publicada especialmente para establecer la regulación normativa y las características y exigencias a éstos tipos contractuales.

\section{c) El alquiler de vivienda para uso turístico}

Esta modalidad arrendaticia para uso turístico formaba parte de los arrendamientos temporales, sometiéndose al mismo régimen jurídico, hasta que en 2013 el Legislador opta por excluirla del ámbito

\footnotetext{
CASTAN TOBEÑAS, J. y CALVILLO MARTINEZ DE ARENAZA, J. (1956, p. 135-142).

Sentencia nuestro Alto Tribunal que es doctrina jurisprudencial superada el hecho de que, cuando un arrendamiento disponga de una serie de prestaciones accesorias, no se regirá por la L.A.U. al ser considerado como un arrendamiento complejo. Primer considerando de la STS de 16 de junio de 1982 (RJ 1982\5828).

16 La propia normativa que regula estos contratos prohíbe el empleo de la denominación "multipropiedad" dado que la utilización del término puede inducir a error ya que lo que se adquiere realmente es un derecho de uso y no de propiedad sobre el alojamiento que va a ocupar temporalmente, como así viene indicado en el art. 23. 4 de la propia norma 4/2012, de 6 de julio, de contratos de aprovechamiento por turno de bienes de uso turístico, de adquisición de productos vacacionales de larga duración, de reventa y de intercambio de normas tributarias, que dispone que "El derecho real de aprovechamiento por turno no podrá en ningún caso vincularse a una cuota indivisa de la propiedad, ni denominarse multipropiedad, ni de cualquier otra manera que contenga la palabra propiedad".

17 Concretamente, en los puntos II y III del Preámbulo se indica que estos contratos son una variante del arrendamiento por temporada y, específicamente, se indica en el art. 23. 6 que estos contratos quedarán sujetos a lo dispuesto en este Título II (de la propia Ley) sin perjuicio de lo prevenido en la Ley 29/1994, de 24 de noviembre, de Arrendamientos Urbanos y en la legislación general de protección del consumidor.

18 Enmienda número 151 de Coalición Canaria. BOCG, número 80-10, p. 94.
} 
normativo de la L.A.U., generando una gran incertidumbre sobre la nueva Legislación a la que debe someterse. Justo a continuación veremos profundizaremos pormenorizadamente en el estudio de los contratos de alquiler para uso turístico.

3.4 Especial analisis del apartado e) del art. 5 de la L.A.U., introducido por la Ley 4/2013, de 4 de junio, que excluye los alquileres turisticos

\subsubsection{El estado de la cuestión}

Hasta la entrada en vigor de la Ley $4 / 2013$, de 4 de junio, este tipo de alquileres para uso turístico celebrados entre particulares estaban circunscritos, como anteriormente hemos comentado, a lo dispuesto en la L.A.U., dentro de los arrendamientos vacacionales, sometiéndose al mismo régimen jurídico. Sin embargo, con el auge de la tecnología y la aparición de las nuevas vías de comunicación, sumado al entorno de crisis económica vivido desde el 2008, propició que el turismo se erigiera como una de las pocas actividades capaces de generar ingresos, tanto a nivel de los profesionales como, esencialmente, para los particulares, que ven de esta manera una fuente de ingresos extra, especialmente con el auge de las plataformas digitales especializadas en la oferta turística entre particulares (Airbnb, homeaway, Windu, etc.).

Así, el uso de este tipo de alquileres ha experimentado un incremento tal que, en 2014, un informe de EXCELTUR (2015) estimó que representaban 2.725.134 de las plazas turísticas ofertadas, en comparación con las 1.433.262 plazas que ofrecieron los hoteles, o más lejanas, las 450.432 que ofrecieron los apartamentos turísticos. Precisamente, como expone Campuzano Tome (2015, p. 1203), tal fue el crecimiento de estas prácticas entre particulares que sobrevino en una alternativa a los alquileres tradicionales, lo que motivó que los establecimientos de alojamiento colectivo, que veían una especie de competencia desleal, presionaran al legislador para que promoviera su regulación y los excluyera del ámbito de aplicación de la legislación civil arrendaticia. Consecuentemente, nuestro Legislador, cediendo en cierto modo a tales presiones y en un intento de evitar situaciones que podrían estar dando cobertura a situaciones de intrusismo y competencia desleal, como así se refleja en su propio preámbulo ${ }^{19}$, procedió a la aprobación de la Ley $4 / 2013$, de 4 de junio.

Mediante esta Ley no se modifica el art. 3.2 de la L.A.U. propio de los arrendamientos por temporada, sino que añade un nuevo apartado al art. 5 de la L.A.U., relativo a los arrendamientos excluidos de su ámbito de aplicación, señalando que "e) La cesión temporal de uso de la totalidad de una vivienda amueblada y equipada en condiciones de uso inmediato, comercializada o promocionada en canales de oferta turística y realizada con finalidad lucrativa, cuando esté sometida a un régimen específico, derivado de su normativa sectorial", sino que se excluye este tipo de alquileres vacacionales de la L.A.U.

Con esta medida, se ha generado una inseguridad jurídica entre los propietarios de viviendas que tradicionalmente las arrendaban, al no tener claro si se les impide seguir desarrollando la actividad locativa de sus inmuebles al amparo de la L.A.U., debiéndose someter a lo que dispuesto en las CC.AA., lo que normalmente supone reunir una serie de requisitos extras administrativos que, en ocasiones, pueden dificultar dicha actividad. Consecuentemente, la gran dificultad que entraña la exclusión de los alquileres para uso turístico radica en el cuándo debe otorgarse al alquiler de un alojamiento privado la calificación de "vacacional" y cuando el de "turístico".

Por ello, vamos a analizar el controvertido apartado e) para esclarecer, en primer lugar, que los arrendamientos vacacionales no quedan ni en desuso ni, tampoco, su utilización al margen de la Ley, y también para marcar la línea que los separa de la modalidad de los "alquileres turísticos".

\footnotetext{
19 Se justifica la reforma de la Ley señalándose que "en los últimos años se viene produciendo un aumento cada vez más significativo del uso del alojamiento privado para el turismo, que podría estar dando cobertura a situaciones de intrusismo y competencia desleal, que van en contra de la calidad de los destinos turísticos; de ahí que la reforma de la Ley propuesta los excluya específicamente para que queden regulados por la normativa sectorial específica o, en su defecto, se les aplique el régimen de los arrendamientos de temporada, que no sufre modificación".
} 


\subsubsection{Interpretación del apartado e) del art. 5.}

Así pues, debido a que el contenido de este apartado no es para nada sencillo ni claro, sino más bien todo lo contrario, confuso y de difícil interpretación, al no concretar y delimitar los requisitos que determinan su exclusión, vamos a analizar cada uno de los aspectos que deben confluir para que se produzca dicha exclusión, que hemos clasificado en 5 apartados.

\section{a) Que exista una cesión temporal de uso de la totalidad de la vivienda}

En cuanto a la CESION TEMPORAL, recordaremos brevemente lo expuesto anteriormente en el apartado de los arrendamientos por temporada, donde el concepto de temporal se contrapone al de necesidad permanente, requisito imprescindible para calificar a los arrendamientos de vivienda del art. 2, indicando que la temporalidad se determinará en función de la necesidad de vivienda (no permanente) que se desee satisfacer, y no por un carácter cuantitativo. Así, si se satisface una necesidad "académica", la temporalidad se determinará por la duración que tengan los estudios, o si es de "segunda residencia", por el tiempo que necesite cubrir esa necesidad, y en el caso de un "periodo vacacional", por el tiempo que tengan de vacaciones. Sin embargo, la principal dificultad de este requisito se nos presenta en las cesiones de uso por "periodos vacacionales", y no precisamente por la temporalidad o duración del mismo, sino por el calificativo de "vacacional", en contraposición a "turístico", siendo este el aspecto fundamental sobre el que orbitará el régimen jurídico aplicable a los mismos.

Respecto a LA TOTALIDAD DE LA VIVIENDA, se hace referencia a los arrendamientos del art. 3.2, concretamente a los arrendamientos celebrados por temporada. Sobre este particular no hay dudas, al estar claro que ha de arrendarse la totalidad del inmueble. Por el contrario, y profundizando en este aspecto, al estar muy de moda hoy en día el alquiler de habitaciones por estancias cortas de tiempo, cabría plantearse lo siguiente; ¿Qué sucede entonces en los supuestos que el objeto del contrato sea una única habitación? Y más allá, desde la perspectiva contraria, ¿Qué sucede en aquellos supuestos en los que se celebre un arrendamiento de una vivienda para un uso vacacional pero el arrendador se reserve un derecho a utilizar una única habitación dentro de la misma?

Sobre este particular, considero que la referencia expresa a "la totalidad de la vivienda" como un condicionante para su exclusión del ámbito normativo de la L.A.U. es innecesaria, ya que entiendo que la L.A.U. únicamente engloba dentro de su ámbito de aplicación aquellos arrendamientos urbanos que se celebren, única y exclusivamente, sobre la totalidad de una vivienda, quedando directamente excluidos aquellos que no cumplan dicho requisito, como pudiera ser, a título de ejemplo, el contrato de arrendamiento de una habitación, los cuales se obligan a lo establecido inter partes y, supletoriamente, a lo dispuesto en el Código Civil20.

\section{b) Que la vivienda esté amueblada y en condiciones de uso inmediato}

En sentido negativo, el alquiler de una vivienda que no esté amueblada ni en condiciones para ser destinada a uso turístico no estará excluido de la L.A.U. Este apartado excluye los locales de negocio que, generalmente, se alquilan vacios para desempeñar, en los mismos, actividades comerciales e industriales. Con este apartado, el Legislador diferencia, sutilmente, entre los tipos de arrendamiento regulados en el artículo 3 sobre los que hace especial referencia: los celebrados por temporada y los de local de negocio.

Así, mediante la nota de la temporalidad del contrato, entre otras medidas, se reduce el ámbito de aplicación únicamente a los arrendamientos regulados en el art. 3 (los celebrados para un uso distinto del de vivienda), con la exigencia de que esté en condiciones de uso inmediato y que esté amueblado, pues se descartan igualmente los destinados a usos comerciales o industriales que pueden celebrarse sobre viviendas que no estén en condiciones de habitabilidad.

\footnotetext{
20 Sobre este y otros aspectos, consultar mi otro trabajo profundizando sobre este particular. En: HERMOSA (2016, p. 999-1037).
} 


\section{c) Que sea comercializada o promocionada en "canales de oferta turística"}

Por canales de oferta turística podemos entender las agencias de viaje, las inmobiliarias especializadas en turismo, a través de internet... No en cambio, cuando se concierte directamente por el arrendador y el usuario turístico. Este apartado se puede entender como una medida clara de carácter político para enfrentar, preventivamente, al auge de los arrendamientos de viviendas de uso turístico que se viene produciendo en el último lustro gracias a las plataformas online o webs 2.0 y que reflejan una nueva realidad y un nuevo reto jurídico.

Con esta medida el Legislador Estatal cede al autonómico "el testigo" para que sea él, a través de las competencias que tiene cedida por la Constitución en materia de turismo, quien regule ésta actividad y que sea, asimismo, quien asuma el conflicto que se deriva de estas prácticas entre los lobbies hoteleros y los particulares que arriendan, resolviéndose de manera relativamente diferente en función de las diferentes normativas autonómicas. En este sentido, respecto al concepto de canal de oferta turística, engloban diferentes posibilidades que van desde las empresas de mediación y organización de servicios turísticos hasta las mismas agencias de viajes. De este modo, el requisito del "canal de oferta turística" está completamente sometido y condicionado a lo que se disponga en la normativa autonómica correspondiente, no siendo, por tanto, una condición independiente que pueda determinar la exclusión de un alquiler del régimen jurídico de la L.A.U., ya que siempre estará supeditada a lo que se determine en la normativa autonómica que regule específicamente este tipo de arrendamientos.

La concepción de "canal de oferta turística" variará en función de las Comunidades Autónomas que se han pronunciado al respecto. A título de ejemplo, la Comunidad Canaria que engloba dentro de este concepto a "las agencias de viajes, centrales de reserva y otras empresas de intermediación y organización de servicios turísticos, incluidos los canales de intermediación virtuales; páginas webs de promoción, publicidad, reserva o alquiler; y publicidad realizada por cualquier medio de comunicación". ${ }^{21}$ Por su parte, la Comunidad de Aragón, lo define casi en los mismos términos: "las agencias de viajes; centrales de reserva; otras empresas de mediación y organización de servicios turísticos, incluidos los canales de intermediación virtuales; así como la inserción de publicidad en los espacios de los medios de comunicación social relacionados con los viajes y estancias en lugares distintos a los del entorno habitual de los turistas". ${ }^{22}$ La junta de Andalucía, por el contrario, lo define de una forma más laxa incluyendo dentro de este concepto únicamente a" (...) las agencias de viaje, las empresas que medien u organicen servicios turísticos y los canales en los que se incluya la posibilidad de reserva del alojamiento". ${ }^{23}$ Para finalizar, haremos referencia a lo expuesto en la normativa de la Comunidad de Madrid, ${ }^{24}$ que, al contrario de las anteriores normativas, no establece una definición para lo que debe entenderse por "canal de oferta turística", generándose con ello una cierta confusión e incertidumbre.

Finalmente, atendiendo a este requisito, podríamos plantearnos la siguiente cuestión; ¿Qué normativa se aplicará en el supuesto en el que el propietario particular lo promociona a través del boca a boca, o a través del tradicional cartel de "se alquila"? Es decir, ¿A qué régimen jurídico se someten estos alquileres vacacionales cuando no se promocionen a través de lo que se considere como un "canal de oferta turística"? La respuesta, bajo mi punto de vista, es que se someterán a lo dispuesto en la L.A.U., al tratarse de "alquileres vacacionales", aunque es importante resaltar dos cuestiones determinantes para esta respuesta.

La primera, que conocer si existe una regulación específica sobre este tipo de actividades turísticas (no todas las CC.AA lo hacen), ya que son dichas instituciones las responsables de precisar

21 Art. 2, b), del Decreto 113/2015, de 22 de mayo, por el que se aprueba el Reglamento de las viviendas vacacionales de la Comunidad Autónoma de Canarias.

22 Art. 2, b), del Decreto 80/2015, de 5 de mayo, del Gobierno de Aragón, por el que aprueba el Reglamento de las viviendas de uso turístico en Aragón.

23 Art. 3. 3, del Decreto 28/2016, de 2 de febrero, de las viviendas con fines turísticos y de modificación del Decreto 194/2010, de 20 de abril, de establecimientos de apartamentos turísticos.

24 Art. 2. 2, del Decreto 79/2014, de 10 de julio, del Consejo de Gobierno, por el que se regulan los apartamentos turísticos y las viviendas de uso turístico de la Comunidad de Madrid. 
tal concepto. Y la segunda, que entra en juego cuando la respuesta a la primera es afirmativa, ${ }^{25}$ y que consiste en cerciorarnos de que nuestra promoción del alquiler no encaje en la definición que se haga en la correspondiente normativa de "canal de oferta turística", pues, como hemos analizado, dicha definición varía según las CC.AA.

\section{d) Que se realice con finalidad lucrativa}

Este requisito no presenta dudas al respecto ya que si fuera gratuito sería un contrato de comodato.

\section{e) Que esté regulado por un régimen específico derivado de su normativa sectorial}

Es decir, que desempeñe una actividad que esté regulada específicamente por la CC.AA, en el mismo sentido apuntado anteriormente. Bajo mi punto de vista, este es el parámetro más relevante de todos porque, además de que los otros requisitos suelen ser comunes a todos los contratos celebrados por temporada, será el que realmente determine si este tipo de arrendamiento por temporada se regula por la L.A.U. o, en cambio, se excluye de la misma en favor de una normativa sectorial o autonómica.

Para que se puedan excluir del ámbito de aplicación de la L.A.U., es requisito sine quanom que la CC.AA. haya legislado sobre el turismo y, de forma específica, regule administrativamente las actividades mencionadas, ya que no bastará con que únicamente regule el turismo de forma general, pues, como éste mismo apartado indica, ha de estar regulado por un régimen especifico. En este sentido, tan solo se puede entender que una CC.AA. cumple con dicho requisito cuando, en su normativa de turismo, contemple, de forma específica, una categoría especial para el arrendamiento de viviendas celebrado entre particulares, al margen de que este situado en edificios o complejos turísticos, y reuniendo asimismo los otros requisitos anteriormente comentados. En el supuesto contrario, entiendo que tales alquileres seguirían estando sometidos al régimen jurídico de los arrendamientos por temporada. ${ }^{26}$

Por otro lado, siguiendo la lógica que se desprende del tenor literal del precepto, el nuevo apartado e) del art. 5 no aporta nada nuevo a lo ya establecido en la propia L.A.U., ya que, para que se excluyan estos alquileres de la norma, es imprescindible que las diferentes CC.AA. hayan regulado, específicamente, sobre dicho particular, hipótesis en la cual se presenta innecesaria dicha reforma, al entenderse ya excluidos dichos arrendamientos, en base a las competencias transferidas a las CC.AA. En este caso, al tratarse de acciones concretas recogidas por normas especiales, quedarían automáticamente excluidas del ámbito de aplicación de LA L.A.U. sin necesidad de precisarlo en la propia L.A.U., como es el caso de la multipropiedad y los arrendamientos complejos, que a pesar de ser supuestos de hecho objeto de ser regulados por dicha norma como arrendamientos por temporada, se excluyen por venir desarrollados y regulados en otras normas más especificas. ${ }^{27}$ Consecuentemente, en caso de que la CC.AA. no lo regule escrupulosamente, entiendo que los propietarios de viviendas que arrienden sus viviendas de forma vacacional, seguirán sometiéndose al régimen jurídico de los arrendamientos por temporada previsto en el art. 3.2 de la L.A.U., como así sucede en la gran mayoría de Comunidades Autónomas, que carecen de regímenes específicos para el arrendamiento de viviendas particulares a turistas en su normativa sectorial. ${ }^{28}$

\section{Identificación de los "alquileres vacacionales" y los "alquileres turísticos"}

Bajo mi punto de vista, esta es la cuestión fundamental que hemos de resolver. Hemos de tener claro cuándo un contrato de alquiler de vivienda entre particulares para un uso temporal de vacaciones debe someterse a lo dispuesto en la L.A.U., con la enorme libertad contractual que ello supone para las partes,

\footnotetext{
En caso de que no lo regulen, directamente el apartado e) del art. 5 no tendrá ninguna eficacia.

En el mismo sentido, Alejandro Román Márquez (2014, p. 12)

En el mismo sentido, Herminia Campuzano Tomé (2015, p. 1207).

En el mismo sentido, Alejandro Román Márquez (2014, p. 12).
} 
o por el contrario, cuándo ese mismo contrato deberá entenderse excluido de esa normativa, para remitirse lo establecido en la normativa autonómica, quedando la libertad contractual de las partes drásticamente limitada al riguroso control y potestad sancionadora que de ella se deriva. ${ }^{29}$

La respuesta a este aspecto la encontramos en las diferentes normativas autonómicas en materia de turismo que, de forma específica, hayan regulado la actividad turística otorgando un régimen particular a este tipo de alquileres. Así, el criterio que establece cuándo un alquiler debe ser considerado "vacacional" y cuándo "de uso turístico", es el de la "habitualidad", en referencia al número de veces que desarrollen tal actividad, un concepto que cada normativa autonómica va a delimitar de forma diferente. Consecuentemente, dependiendo de la normativa autonómica a la que acudamos, la línea que delimitará si un arrendamiento deberá calificarse como "vacacional" o, por el contrario, como "turístico", variará en función de lo que cada autonomía haya establecido como "habitualidad".

Sobre este criterio, vamos a ver que en materia de alquileres turísticos, veremos que se determina desde dos direcciones o perspectivas diferentes.

Así, se establece un primer plazo-momento, desde el cual se entiende que comienza la "habitualidad" de la actividad turística, factor que determinará la exclusión del contrato de alquiler del ámbito de aplicación de la L.A.U. en favor de la normativa autonómica. $Y$ en segundo lugar, se establece otro plazo para determinar en qué momento esa "habitualidad" sobrepasará los límites de lo que hemos de considerar turística, factor que, en este caso, en el sentido inverso del anterior, determinará cuándo un contrato de alquiler dejará de someterse al ámbito de aplicación de la especifica normativa autonómica, sometiéndose al régimen jurídico establecido para los arrendamientos por temporada de la L.A.U.

Recapitulando, el concepto de "habitualidad" establecido en la normativa específica de cada CC.AA. es el factor clave que determina cuándo un contrato de alquiler de vivienda entre particulares se califica como de "uso vacacional" y cuándo de "uso turístico", con las importantísimas y diferentes consecuencias jurídicas que de ello se deriva. En este sentido, vamos a ver, a título de ejemplo, cómo se han determinado estos límites, de formas muy distintas, tanto en Andalucía y como en las Canarias.

La normativa de la Junta de Andalucía, a mi juicio, de forma sorprendente, asocia la "habitualidad" al mero hecho de promocionar una vivienda a través de los "canales de promoción turística". Así, consideran "viviendas turísticas" aquellas que se ceden de forma "habitual" y con fines turísticos a cambio de un precio, considerando la "habitualidad" inherente a la oferta en canales turísticos. ${ }^{30}$ Es decir, en Andalucía se entiende que una vivienda se cede de forma habitual por el mero hecho de ofertarla en lo que la propia norma define como canal turístico. En este sentido, se establece el límite inferior o comienzo de la habitualidad desde el mismo momento en que se comercializa a través de un canal turístico. ${ }^{31}$

Por otro lado, en cuanto al límite superior de la "habitualidad", queda fijado en el art. 1. 2, b) en dos meses, al excluirse del ámbito de aplicación a "Las viviendas contratadas por tiempo superior a dos meses computados de forma continuada por una misma persona usuaria". De esta forma, todo alquiler de este tipo que se celebre por una duración ininterrumpida de un mínimo de dos meses, se entiende regulado por el régimen jurídico previsto en la L.A.U. para los arrendamientos por temporada, al ser calificado como un "alquiler vacacional".

En el caso de la normativa Canaria, se entiende que la cesión de una vivienda se producirá "de forma habitual" cuando se realice "[...] dos o más veces dentro del periodo de un año o una vez al año, pero en

29 En el mismo sentido, apunta Verdera Izquierdo (2009, p. 4) que la cuestión a dilucidar es cuándo un concreto arriendo temporal se debe calificar como arrendamiento de temporada, estancia turística en vivienda o aprovechamiento por turno de bienes inmuebles.

30 Art. 3.2. del Decreto 28/2016, de 2 de febrero, de las viviendas con fines turísticos y de modificación del Decreto 194/2010, de 20 de abril, de establecimientos de apartamentos turísticos.

31 Considero que esta medida restringe flagrantemente la libertad contractual de las partes y restringe la libertad de disposición de bienes de los ciudadanos imponiéndose institucionalmente una serie de medidas y condiciones a su simple uso. En el mismo sentido, señala CAMPUZANO TOMÉ (2015, p. 1212). que “"Algunos legisladores autonómicos no dudan en erigirse con autoridad y potestad suficiente para atribuirse competencias que no le corresponden, controlando y sancionando como turísticos arrendamientos que claramente gozan de una naturaleza civil y que, por tanto, deben quedar sometidos al régimen jurídico de la legislación de arrendamientos urbanos". 
repetidas ocasiones". ${ }^{32} \mathrm{Al}$ contrario de lo regulado en Andalucía, en Canarias se presume la "habitualidad" la segunda vez que se alquile la vivienda, lo cual deja un pequeño margen a los propietarios particulares que deseen alquilar sus viviendas, sometiéndose el primer contrato de alquiler del año al régimen jurídico dispuesto para los arrendamientos por temporada de la L.A.U.

Por lo que respecta al límite máximo del concepto de "habitualidad", al contrario que en Andalucía, la normativa canaria no marca expresamente un límite máximo a la cesión de una vivienda de "uso turístico", sino que la extraemos del art. 2. d), íntimamente ligado al concepto de habitualidad, que fija que la "cesión temporal" de una vivienda mediante la figura del "alquiler de una vivienda vacacional" no podrá implicar el cambio de residencia por parte de la persona usuaria, que desde la perspectiva tributaria, y de forma general, ${ }^{33}$ se establece en 6 meses.

\section{Conclusiones}

El arrendamiento vacacional no es un contrato tipo que venga específicamente recogido en la L.A.U. Se trata de una clasificación que se deduce del estudio de los arrendamientos urbanos celebrados por temporada recogido en el art. 3. 2 de la misma norma.

Aunque no venga estipulado en la norma, el objeto del contrato deberá recaer, en todo caso, sobre una edificación habitable, es decir, una vivienda en condiciones de ser habitada. Asimismo, dicha vivienda deberá estar amueblada y en condiciones de utilización inmediata.

El apartado e) del art. 5 de la L.A.U. no convierte a los alquileres vacacionales en ilegales, sino que su aplicación se volverá suplementaria. Es decir, únicamente un contrato de alquiler de una vivienda celebrado entre particulares podrá someterse al régimen jurídico de los alquileres vacacionales en caso de que no exista una normativa autonómica especifica que regule los alquileres turísticos o porque en ella misma así se disponga.

El factor que delimita los alquileres vacacionales y los turísticos es la habitualidad, concepto que ha de venir definido en la normativa autonómica.

En caso de que un contrato de alquiler celebrado entre particulares por una temporada vacacional no venga estrictamente regulado por una normativa autonómica, su régimen jurídico quedara sujeto a lo dispuesto en el art. 3. 2 de la L.A.U. relativo a los alquileres vacacionales, como una clase de arrendamiento temporal.

\section{Referencias}

ALBACAR, En VALPUESTA FERNANDEZ, M R. Articulo 3. Arrendamientos para uso distinto del de vivienda. En: Valpuesta Fernández, $\mathrm{M}^{\circ} \mathrm{R}$ (Coord.). Comentarios a La Nueva Ley de Arrendamientos Urbanos. Valencia: Tirant lo Blanch, 1994.

BOTELLO HERMOSA, Jose Maria. El contrato de arrendamiento de habitación. La problemática de su regulación ¿Ley de Arrendamientos Urbanos o Código Civil. Revista Critica del Derecho Inmobiliario, n. 754, 2016.

CAMPUZANO TOMÉ, Herminia. "El alquiler de viviendas de uso turístico a partir de la Ley 4/2013: la necesaria interpretación conjunta de la LAU y de la legislación turística autonómica". Revista Crítica de Derecho Inmobiliario, n. 749, 2015, p. 1199-1246.

Art. 2 c) del Decreto 113/2015, de 22 de mayo, por el que se aprueba el Reglamento de las viviendas vacacionales de la Comunidad Autónoma de Canarias.

33 Art. 9.1 a), de la Ley 35/2006, de 28 de noviembre, del Impuesto sobre la Renta de las Personas Físicas y de modificación parcial de las leyes de los Impuestos sobre Sociedades, sobre la Renta de no Residentes y sobre el Patrimonio. 
CASTAN TOBEÑAS, J.; CALVILLO MARTINEZ DE ARENAZA, J. Tratado practico de arrendamientos urbanos. Parte General. Madrid: Reus, 1956. t. I.

COLINA GAREA, Rafael. El Arrendamiento de Vivienda Por Temporada Académica. Barcelona: Cedecs, 1998.

DAVILA GONZALEZ, D. Art.3. ‥ En: V. Guilarte Gutiérrez (director), LAU La Nueva Ley De Arrendamientos Urbanos. Valladolid: Lex Nova, 1994.

DIEGO, C. DE. Instituciones de Derecho civil español. 2. Madrid, 1930. t. II.

EXCELTUR. Alojamiento turístico en viviendas de alquiler: impactos y retos asociados. 2015. Recuperado de: <http://www.exceltur.org/wp-content/uploads/2015/01/Informe-Perspectivas-N51Balance-2014-y-perspectivas-2015-Definitivo-Web.pdf>.

FUENTES LOJO. En VALPUESTA FERNANDEZ, $M^{\circ}$ R. Articulo 3. Arrendamientos para uso distinto del de vivienda. En: Valpuesta Fernández, $M^{\circ} \mathrm{R}$ (Coord.). Comentarios a La Nueva Ley de Arrendamientos Urbanos. Valencia: Tirant lo Blanch, 1994.

GUILARTE ZAPATERO, V. Artículos 1 a 8. En: Xavier O' Callaghan (Director). Comentarios a la Ley de Arrendamientos Urbanos (Ley 29/1994, de 24 de noviembre). Madrid: Edersa, 1995.

O'CALLAGHAN, X. Introducción. En: O'CALLAGHAN, X. (Coord.). Comentarios a la Ley de Arrendamientos Urbanos. Madri: Edersa, 1995.

ORDÁS ALONSO, M.; VALLADARES RASCON, E. Art. 3, Arrendamiento para uso distinto del de vivienda. En: R. Bercovitz Rodríguez-Cano (Coord.). Comentarios a la ley de arrendamientos urbanos. Navarra: Aranzadi, 2013.

PÉREZ SERRANO, N. El contrato de hospedaje en su doble aspecto civil y mercantil. Madrid, Imprenta del asilo de Huérfanos del Sagrado Corazón de Jesús, 1930.

ROMÁN MÁRQUEZ, Alejandro. Las viviendas particulares dedicadas a la actividad de alojamiento turístico. Su exclusión de la ley de arrendamientos urbanos. Revista Internacional de Jurisprudencia, 2014, n. 6.

ROJO AJURIA, L. Comentario a la Ley de Arrendamientos Urbanos. PANTALEON PRIETO, F. (director). Madrid: Civitas, 1995.

VATIER FUENZALIDA, C. Art. 3. ${ }^{\circ}$. Arrendamientos para usos distintos del de vivienda. En: Lasarte Álvarez, C. (Coord.). Comentarios a la Ley de Arrendamientos Urbanos. Madrid: Tecnos, 1996.

VALPUESTA FERNANDEZ, Mํ R. Articulo 3. Arrendamientos para uso distinto del de vivienda. En: Valpuesta Fernández, $\mathrm{M}^{\circ} \mathrm{R}$ (Coord.). Comentarios a La Nueva Ley de Arrendamientos Urbanos. Valencia: Tirant lo Blanch, 1994.

VERDERA IZQUIERDO, Beatriz. El arrendamiento de temporada frente a las estancias turísticas en viviendas. Revista Consultor inmobiliario, n. 107, p. 3-19. 2009.

YUFERA SALES, Pedro L. Arrendamientos Urbanos. Análisis practico de la normativa arrendaticia aplicable, sistematizada por conceptos Barcelona: Bosch, 2000.

Recebido em: 28/06/2017

Aprovado em: 10/07/2017 